Supporting Information for

\title{
MXene-Based Aerogel Anchored with Antimony Single Atoms and Quantum Dots for High- Performance Potassium-Ion Batteries
}

Xin Guo, ${ }^{\dagger, \#}$ Hong Gao, ${ }^{\ddagger}, \#$ Shijian Wang, ${ }^{\dagger, \#}$ Guang Yang, ${ }^{\|}$Xiuyun Zhang, *, Jinqiang

Zhang, ${ }^{\dagger}$ Hao Liv ${ }^{* \dagger}$ and Guoxiu Wang ${ }^{*, \dagger}$

${ }^{\dagger}$ Centre for Clean Energy Technology, School of Mathematics and Physics, Faculty of Science, University of Technology Sydney, Broadway, Sydney NSW 2007, Australia

¥Joint International Laboratory on Environmental and Energy Frontier Materials, School of Environmental and Chemical Engineering, Shanghai University, Shanghai 200444, China

'College of Physical Science and Technology, Yangzhou University, Yangzhou 225002, China

\#These authors contributed equally to this work.

*Emails: xyzhang@yzu.edu.cn; hao.liu@uts.edu.au; Guoxiu.Wang@uts.edu.au. 


\section{Experimental Section}

\section{Materials Synthesis}

Synthesis of few-layered MXene $\left(\mathrm{Ti}_{3} \mathrm{C}_{2} \mathrm{~T}_{x}\right)$. The $\mathrm{Ti}_{3} \mathrm{C}_{2} \mathrm{~T}_{\mathrm{x}}$ was obtained by etching the MAX $\mathrm{Ti}_{3} \mathrm{AlC}_{2}$ material. Typically, $1 \mathrm{~g}$ of $\mathrm{LiF}$ was added into $10 \mathrm{ml}$ of $9 \mathrm{M} \mathrm{HCl}$ solution under stirring. After the salt absolutely dissolved in the solution, $1 \mathrm{~g}$ of $\mathrm{Ti}_{3} \mathrm{AlC}_{2}$ powder was slowly added into the mixture. The reaction mixture was kept stirring for $24 \mathrm{~h}$, then centrifuged and washed by distilled water several times until the $\mathrm{pH}$ of the supernatant arrived at 6. Subsequently, the sediment was re-dispersed in $200 \mathrm{ml}$ DI water, which was sonicated under bubbling Ar for $1 \mathrm{~h}$. Thereafter, the suspension was centrifuged at $3500 \mathrm{rpm}$ for $1 \mathrm{~h}$, and the supernatant was collected for further experiment. The supernatant was a stable colloidal solution of few-layered $\mathrm{Ti}_{3} \mathrm{C}_{2} \mathrm{~T}_{\mathrm{x}}$ flakes; the concentration of the colloidal was evaluated by vacuum-assisted filtration of a certain volume of solution and measuring the weight after drying at room temperature overnight.

Synthesis of graphene oxide (GO). The GO was prepared by a modified Hummer method. Typically, natural graphite fakes (1.0 g, Sigma-Aldrich), $\mathrm{NaNO}_{3}(1.0 \mathrm{~g})$, and $\mathrm{H}_{2} \mathrm{SO}_{4}(98 \mathrm{wt} \%, 48 \mathrm{~mL})$ were mixed and stirred in an ice bath, and $6 \mathrm{~g}$ of $\mathrm{KMnO}_{4}$ was slowly added into the mixture. After mixing for $30 \mathrm{~min}$, the ice bath was removed, and the mixture was further stirred for $48 \mathrm{~h}$. Next, distilled water $(90 \mathrm{~mL})$ was added under stirring while the temperature was rose to $60{ }^{\circ} \mathrm{C}$. Finally, $\mathrm{H}_{2} \mathrm{O}\left(240 \mathrm{~mL}, 60{ }^{\circ} \mathrm{C}\right)$ was added, followed by the slow addition of $\mathrm{H}_{2} \mathrm{O}_{2}(15 \mathrm{~mL}, 30 \%)$. The final suspension was centrifuged, washed, and dialyzed with water to obtain graphene oxide. The as- 
synthesized graphene oxide was dispersed into distilled water and sonicated for $2 \mathrm{~h}$ to form a homogeneous colloidal solution.

Preparation of the Sb SQ@MA composite. $5 \mathrm{ml}$ of $\mathrm{Ti}_{3} \mathrm{C}_{2} \mathrm{~T}_{\mathrm{x}} \mathrm{MXene}\left(3 \mathrm{mg} \mathrm{ml}^{-1}\right)$ colloidal solution and $10 \mathrm{ml}$ of dissolved citric acid solution $(0.1 \mathrm{M})$ were homogenously mixed under magnetic stirring. Then $0.4 \mathrm{mmol} \mathrm{SbCl}_{3}(97 \%$, Sigma-Aldrich) ethanol solution was dropwise added into the mixture to form a transparent solution, which was kept stirred for $1 \mathrm{~h}$. Secondly, $5 \mathrm{ml}$ of few-layer GO $\left(3 \mathrm{mg} \mathrm{ml}^{-1}\right)$ was poured into the solution, and the mixture was sonicated for 10 mins under Ar bubbling before transferring to a Teflon-lined stainless-steel autoclave. Subsequently, the sealed reactor was placed at $120{ }^{\circ} \mathrm{C}$ for $12 \mathrm{~h}$ to obtain a cylindrical precursor, which was washed by DI water and then freeze-dried under vacuum. Lastly, the dried material was calcined at $450{ }^{\circ} \mathrm{C}$ for $2 \mathrm{~h}$ under the $10 \% \mathrm{H}_{2} / \mathrm{Ar}$ atmosphere to get the final product.

Preparation of the Sb NP@MA composite, pure Sb nanoparticles, and $\mathrm{Ti}_{3} \mathrm{C}_{2} \mathrm{~T}_{x} /$ graphene. The $\mathrm{SbNPs} @ \mathrm{Ti}_{3} \mathrm{C}_{2} \mathrm{~T}_{\mathrm{x}}$ composite sample was synthesized via a similar route without the addition of citric acid as the chelating agent. Pure $\mathrm{Sb}$ nanocrystals were synthesized by the same procedures but using an equaling volume of DI water to substitute the $\mathrm{Ti}_{3} \mathrm{C}_{2} \mathrm{~T}_{\mathrm{x}}$ and GO colloidal solution.

\section{Materials Characterization}

The structure of samples was observed by the field-emission scanning electron microscopy (FE-SEM, Zeiss Supra 55VP) and scanning transmission electron microscopy (STEM, JEOL JEM-ARM200F). The XRD patterns were collected via a Bruker D8 Discovery X-ray diffractometer, and Raman spectra were obtained by a 
Renishaw inVia Raman spectrometer system (Gloucestershire, UK) using a $633 \mathrm{~nm}$ wavelength laser. Nitrogen-sorption measurements were conducted with a Micromeritics 3Flex surface characterization analyzer. XPS analysis was performed through an ESCALAB250Xi (Thermo Scientific, UK) spectroscopy equipped with mono-chromated Al K alpha (energy $1486.68 \mathrm{eV}$ ).

\section{Electrochemical Measurements}

The electrochemical performance of the materials was evaluated in CR2032-type coin cells with $\mathrm{K}$ metal foil as the counter/reference electrode, $40 \mu \mathrm{L}$ of 1 M KFSI in ethylene carbonate (EC), and propylene carbonate (PC) $(1: 1, \mathrm{v} / \mathrm{v})$ as the electrolyte and Celgard 2400 as the separator. The working electrodes were prepared by pasting a uniform aqueous slurry consisting of $70 \mathrm{wt} \%$ active material, $20 \mathrm{wt} \%$ carbon black, and $10 \mathrm{wt} \%$ carboxymethyl cellulose (CMC) onto a copper foil, and then vacuum drying at $80{ }^{\circ} \mathrm{C}$ for $12 \mathrm{~h}$. The typical loading of the tailored round electrode (14 $\mathrm{mm}$ in diameter) was around $1 \mathrm{mg} \mathrm{cm}^{-2}$. Galvanostatic discharge/charge measurements were performed on a Neware battery testing system. The current densities and specific capacities were all calculated based on the mass of $\mathrm{Sb}$ in the electrodes. Cyclic voltammograms were collected in the voltage range of $0 \sim 2.5 \mathrm{~V}$ using a Biologic VMP3 workstation. Moreover, electrochemical impedance spectroscopy (EIS) analyses were performed by applying a potential amplitude of $5 \mathrm{mV}$ to the cells in the frequency range from 100 $\mathrm{kHz}$ to $10 \mathrm{mHz}$.

\section{Computational Methods}

All the theoretical calculations are performed within the Vienna Ab initio Simulation 
Package (VASP) based on density functional theory., 2 The electronic exchangecorrelation interaction is described within the generalized gradient approximation (GGA) of optimized-Perdew-Burke-Ernzerhof (optPBE-vdW) calculation. ${ }^{3}$ The interactions between the ion core and the valence electrons are modeled with projector augmented wave (PAW) potentials. ${ }^{4}$ A plane-wave basis set with a kinetic cutoff energy of $400 \mathrm{eV}$ is employed. The Brillouin zone (BZ) is sampled using $1 \times 1 \times 1$ and $2 \times 2 \times 1$ gamma centered Monkhorst-Pack grids for the calculation of structural relaxation and electronic structures, respectively. The criteria for energy and atom force convergence are set to $10^{-4} \mathrm{eV}$ per unit cell and $0.1 \mathrm{eV} \AA^{-1}$, respectively. We consider two heterojunctions consisting of $\mathrm{Sb}(101)$ and (012) slabs on the $\mathrm{Ti}_{3} \mathrm{C}_{2} \mathrm{~T}_{\mathrm{x}}$. For $\mathrm{Ti}_{3} \mathrm{C}_{2} \mathrm{~T}_{\mathrm{x}} / \mathrm{Sb}$ (101), a $3 \times 6$ supercell of $\mathrm{Ti}_{3} \mathrm{C}_{2} \mathrm{~T}_{\mathrm{x}}$ layer and a $2 \times 4$ supercell of $\mathrm{Sb}$ (101) layer is used, which lattice constants are $15.84 \AA$ and $18.29 \AA$ along with $a$ and $b$ directions, respectively. In this model, 72 of $\mathrm{C}, 108$ of $\mathrm{Ti}$, and 64 of $\mathrm{Sb}$ atoms are included and different terminations of the $\mathrm{Ti}_{3} \mathrm{C}_{2} \mathrm{~T}_{\mathrm{x}}(\mathrm{x}=-\mathrm{O},-\mathrm{F}$, and $-\mathrm{OH}$ groups $)$ were considered separately in the systems. For the Sb SAs incorporated model, two Sb atoms were used to substitute $\mathrm{Ti}$ atoms in the $\mathrm{Ti}_{3} \mathrm{C}_{2} \mathrm{~T}_{\mathrm{x}}$ configuration. As for $\mathrm{Ti}_{3} \mathrm{C}_{2} / \mathrm{Sb}(012)$, a $4 \times 4$ supercell for the $\mathrm{Ti}_{3} \mathrm{C}_{2}$ layer and $1 \times 4$ supercell of $\mathrm{Sb}(012)$ slab are used with a lattice parameter of $21.93 \AA$ and $13.84 \AA$ along with $a$ and $b$ directions, respectively. 


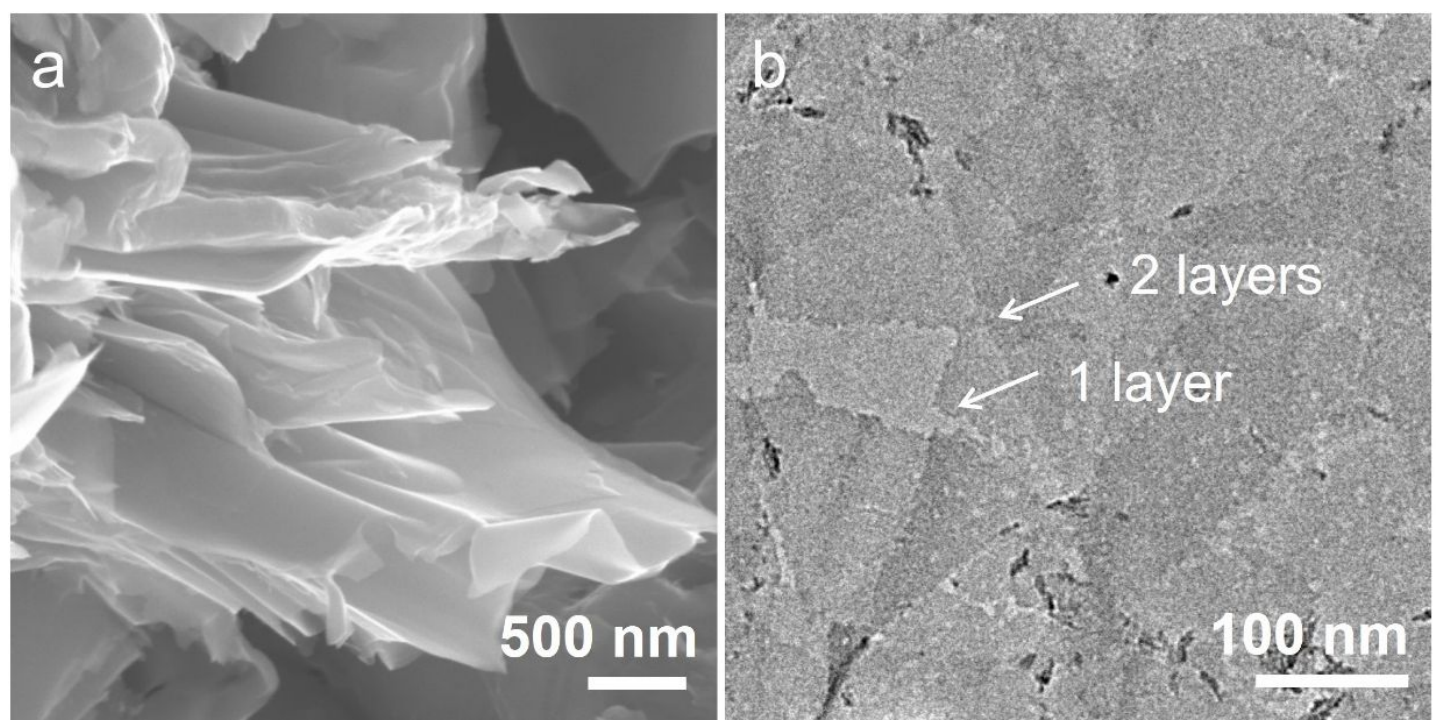

Figure S1. (a) SEM and (b) TEM images of the as-prepared $\mathrm{Ti}_{3} \mathrm{C}_{2} \mathrm{~T}_{\mathrm{x}}$. 


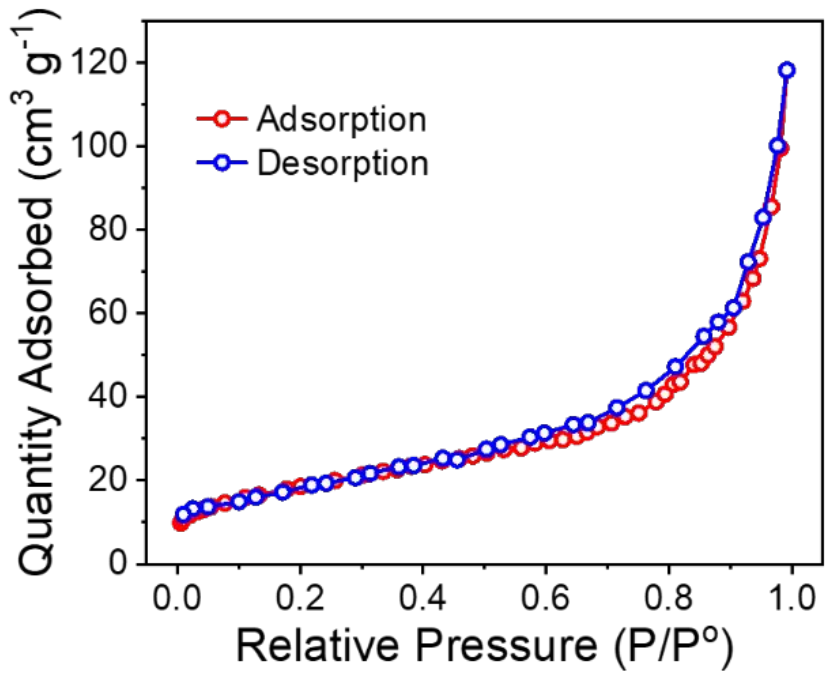

Figure S2. Nitrogen adsorption/desorption isotherms of the Sb SQ@MA composite.

The surface area is calculated by Brunauer-Emmett-Teller (BET) method. 


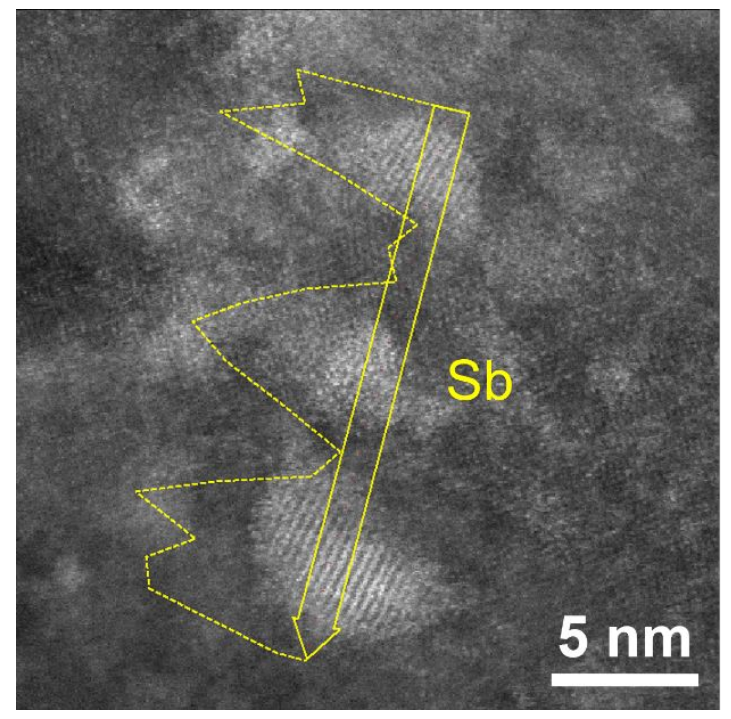

Figure S3. HAADF-STEM images of the Sb SQ@MA composite and the corresponding line profile of the Sb element (yellow arrow). 


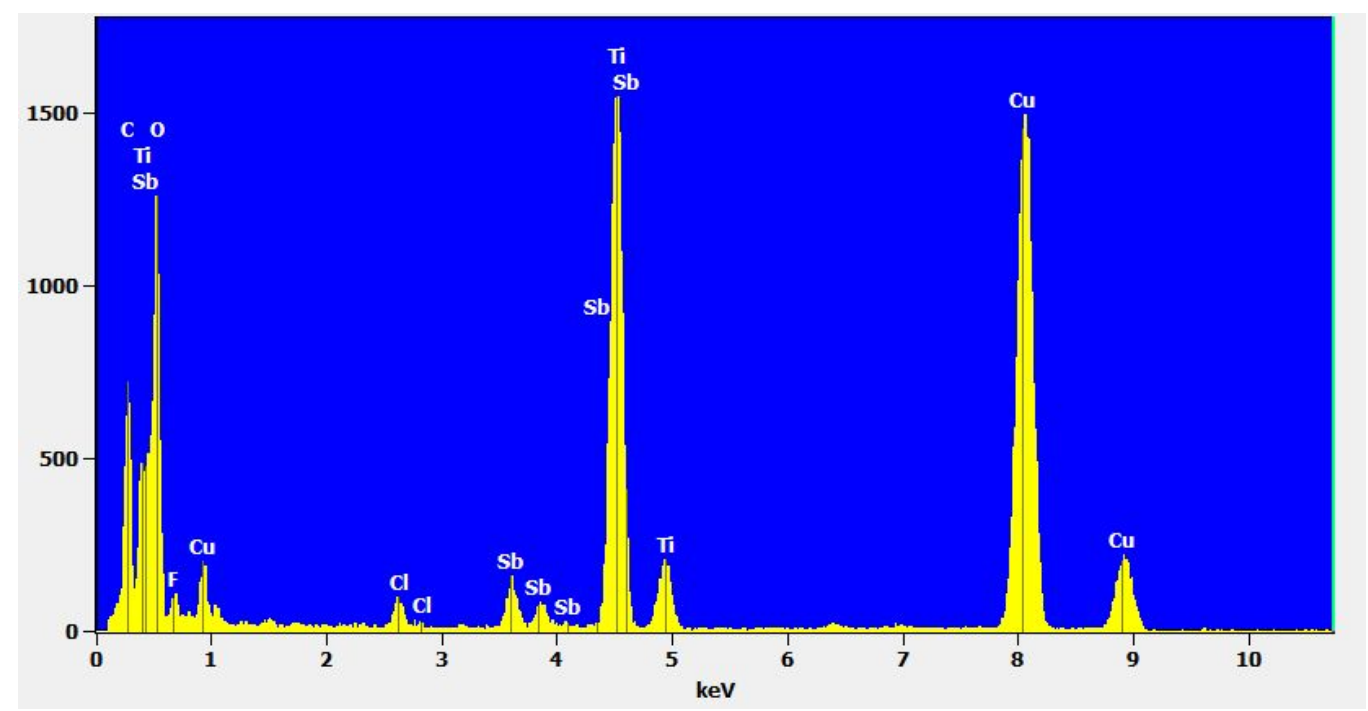

Figure S4. EDX spectrum of the Sb SQ@MA composite. 

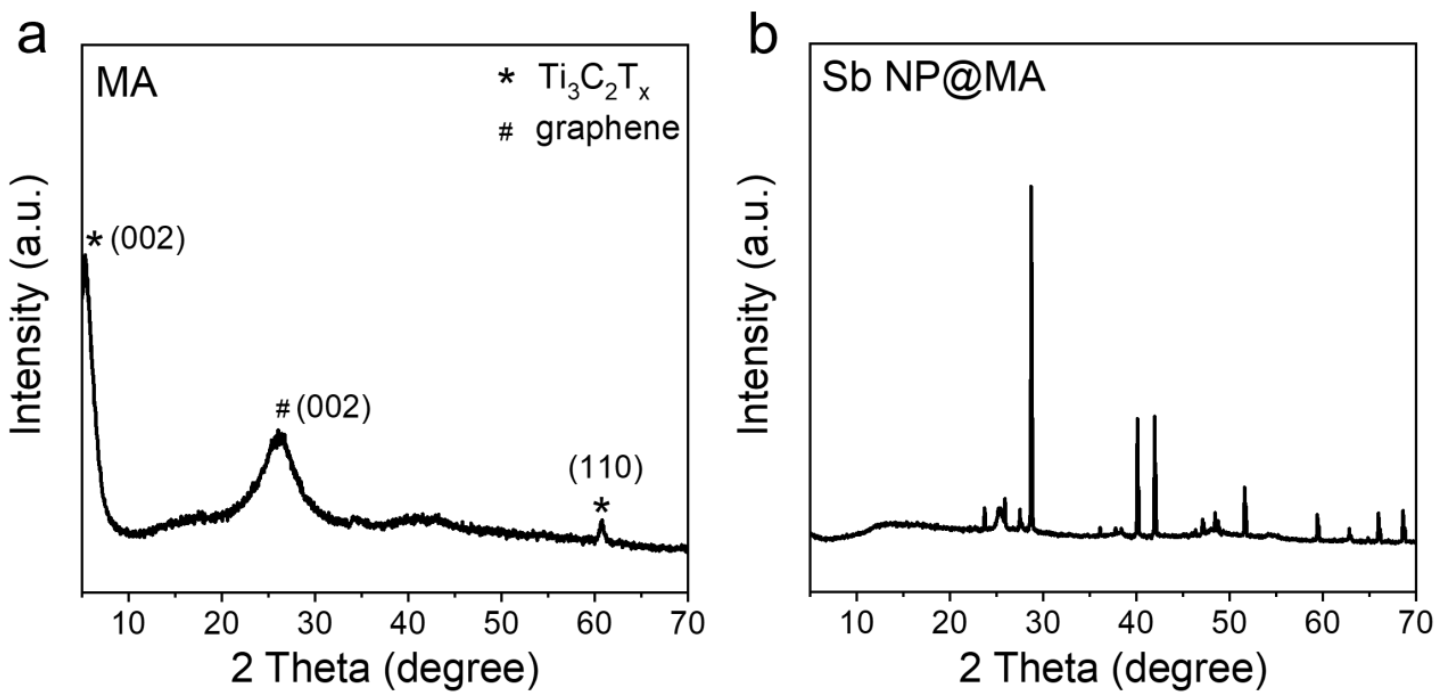

Figure S5. XRD patterns of the (a) MA $\left(\mathrm{Ti}_{3} \mathrm{C}_{2} \mathrm{~T}_{\mathrm{x}}\right.$ MXene based aerogel) and (b) $\mathrm{Sb}$ NP@MA materials. 


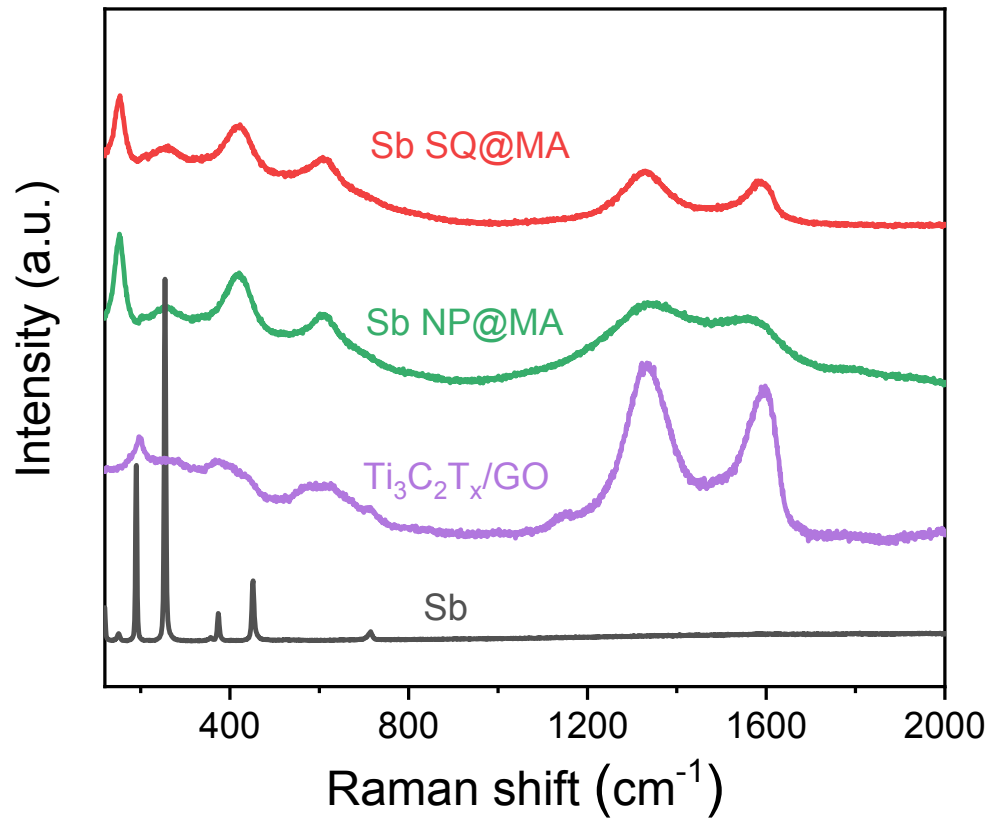

Figure S6. Raman spectra of the Sb, MA, Sb NP@MA, and Sb SQ@MA materials. 

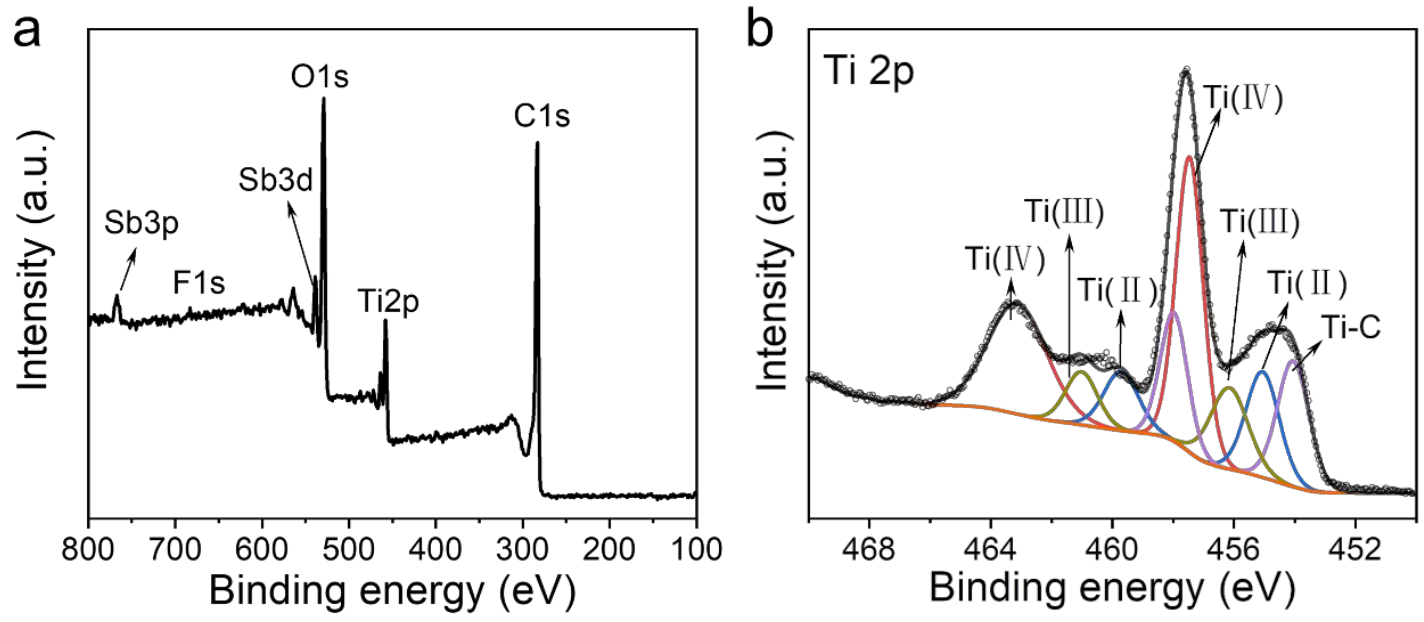

Figure S7. (a) Full survey and (b) Ti 2p XPS spectra of the Sb SQ@MA composite.

Table S1. XPS quantitative analysis results of the detected elements in the Sb SQ@MA composite.

\begin{tabular}{|l|c|c|c|c|c|}
\hline Elements & $\mathrm{C}$ & $\mathrm{Ti}$ & $\mathrm{Sb}$ & $\mathrm{O}$ & $\mathrm{F}$ \\
\hline Atomic\% & 60.86 & 9.12 & 17.18 & 12.38 & 0.46 \\
\hline
\end{tabular}



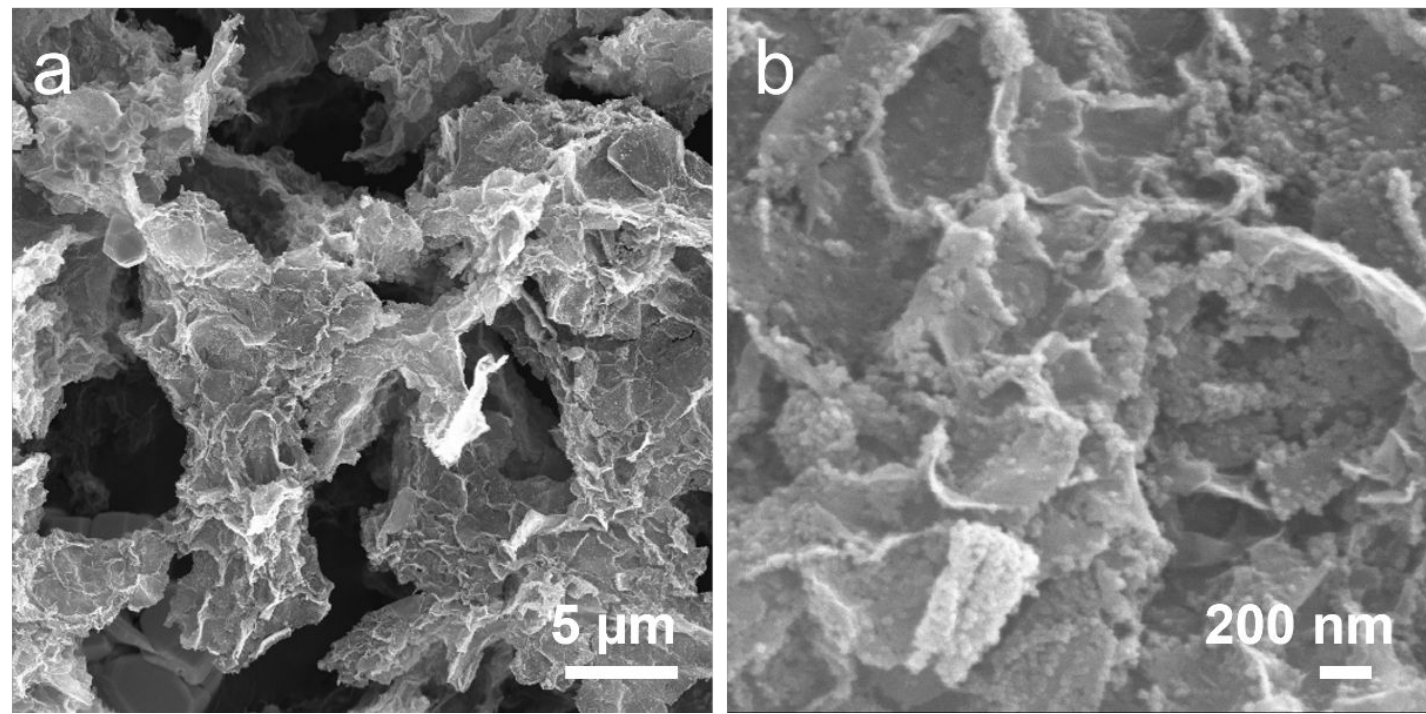

Figure S8. (a) Low-magnification and (b) high-magnification SEM images of the Sb NP@MA composite. 

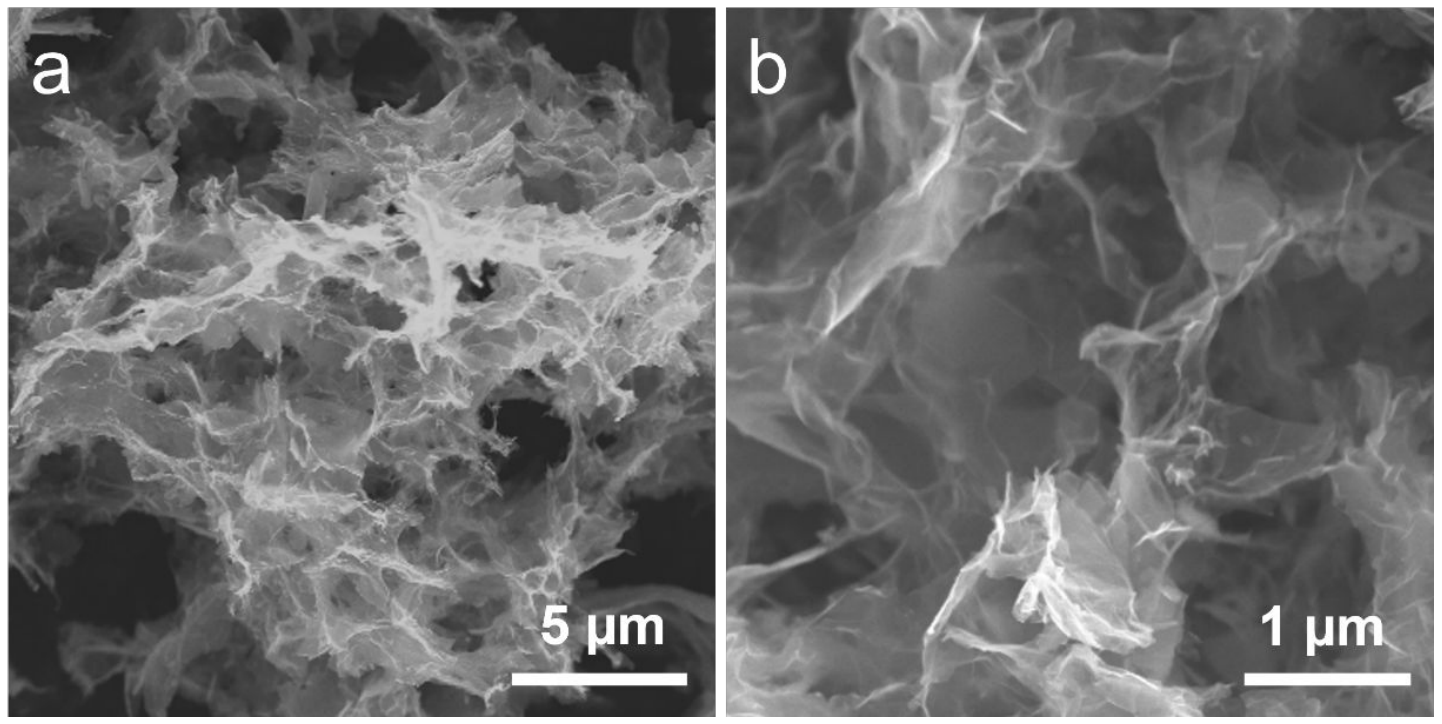

Figure S9. (a) Low-magnification and (b) high-magnification SEM images of the MA. 


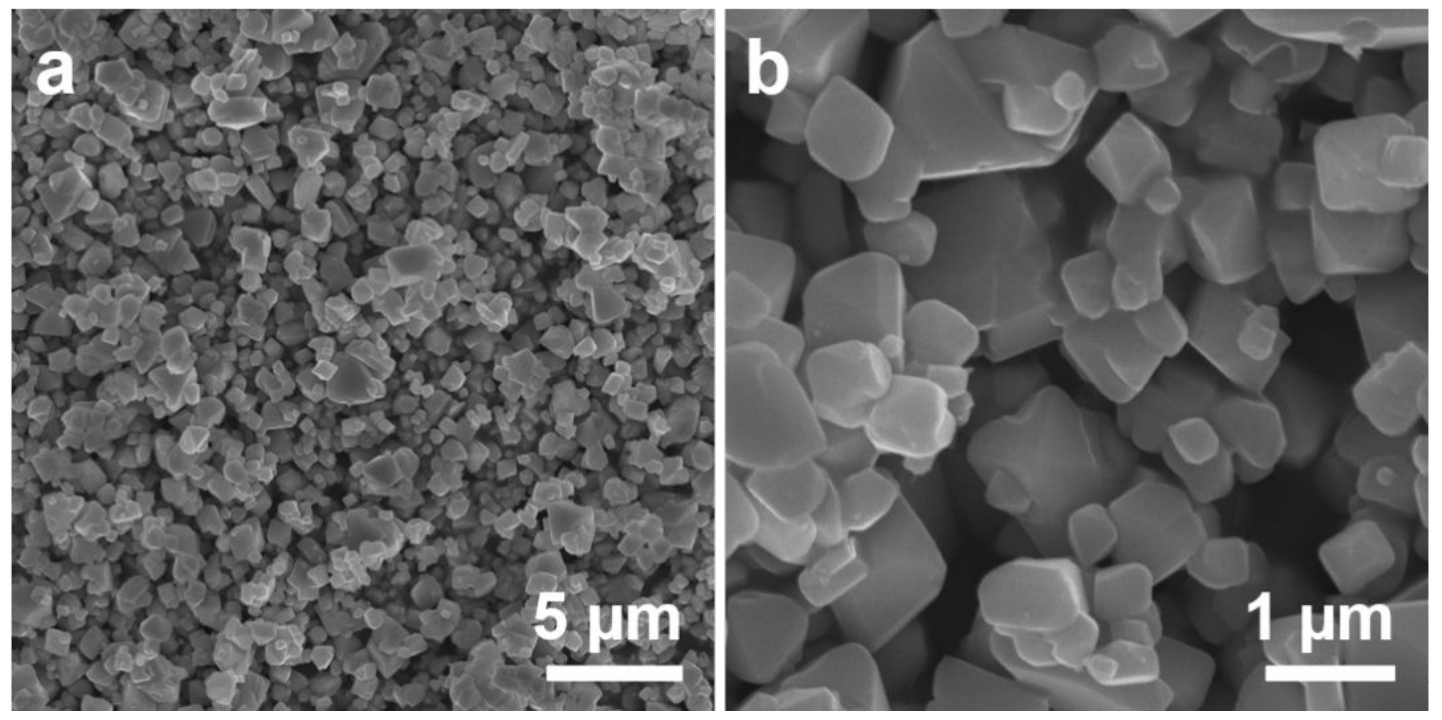

Figure S10. (a) Low-magnification and (b) high-magnification SEM images of the pure

Sb nanoparticles. 

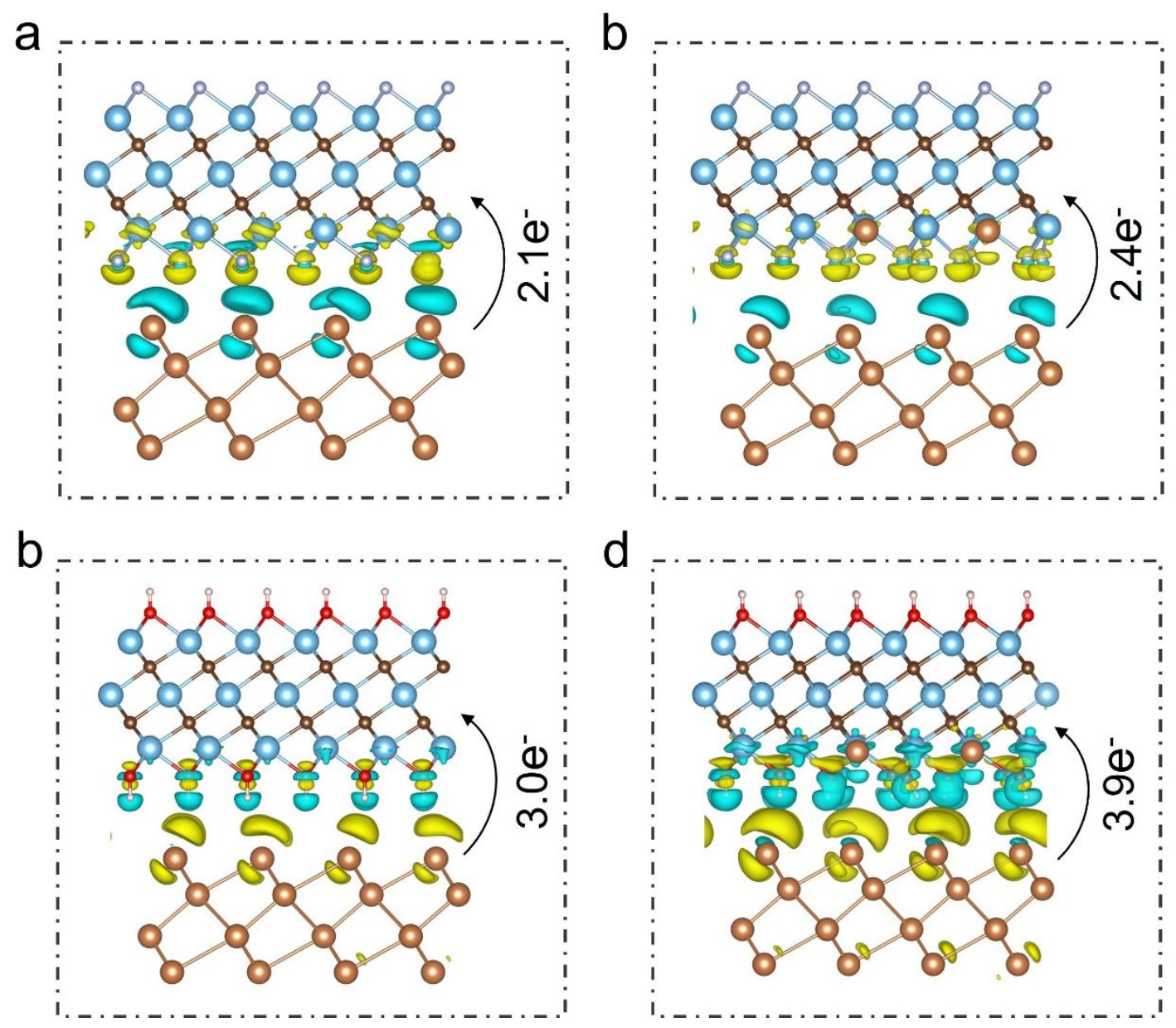

Figure $\mathrm{S} 11$. Charge density difference of (a) $\mathrm{Sb} / \mathrm{Ti}_{3} \mathrm{C}_{2} \mathrm{~F}_{2}$, (b) $\mathrm{Sb} / \mathrm{Ti}_{3} \mathrm{C}_{2} \mathrm{~F}_{2}-\mathrm{Sb}_{\mathrm{SA}}$, (c)

$\mathrm{Sb} / \mathrm{Ti}_{3} \mathrm{C}_{2}(\mathrm{OH})_{2}$ and (d) $\mathrm{Sb} / \mathrm{Ti}_{3} \mathrm{C}_{2}(\mathrm{OH})_{2}-\mathrm{Sb}_{\mathrm{SA}}$. The cyan, light cyan, dark brown, light brown, red, and white balls represent $\mathrm{Ti}, \mathrm{F}, \mathrm{C}, \mathrm{Sb}, \mathrm{O}$, and $\mathrm{H}$ atoms, respectively. 

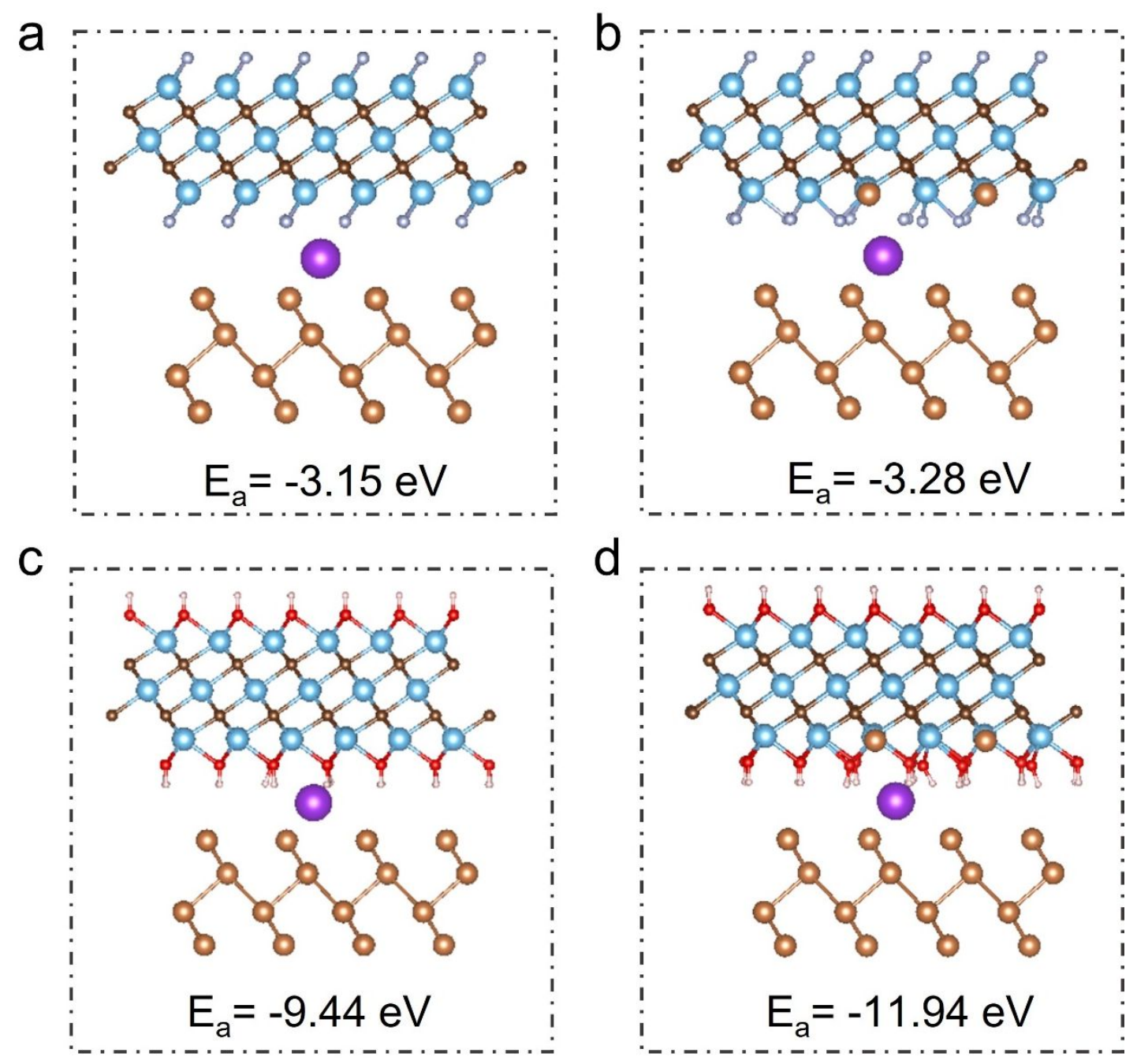

Figure S12. Side views of the most stable K adsorption positions and corresponding adsorption energies at the interface of (a) $\mathrm{Sb} / \mathrm{Ti}_{3} \mathrm{C}_{2} \mathrm{~F}_{2}$, (b) $\mathrm{Sb} / \mathrm{Ti}_{3} \mathrm{C}_{2} \mathrm{~F}_{2}-\mathrm{Sb}_{\mathrm{SA}}$, (c) $\mathrm{Sb} / \mathrm{Ti}_{3} \mathrm{C}_{2}(\mathrm{OH})_{2}$ and (d) $\mathrm{Sb} / \mathrm{Ti}_{3} \mathrm{C}_{2}(\mathrm{OH})_{2}-\mathrm{Sb}_{\mathrm{SA}}$. The cyan, light cyan, dark brown, light brown, red, white, and purple balls represent $\mathrm{Ti}, \mathrm{F}, \mathrm{C}, \mathrm{Sb}, \mathrm{O}, \mathrm{H}$, and $\mathrm{K}$ atoms, respectively. 

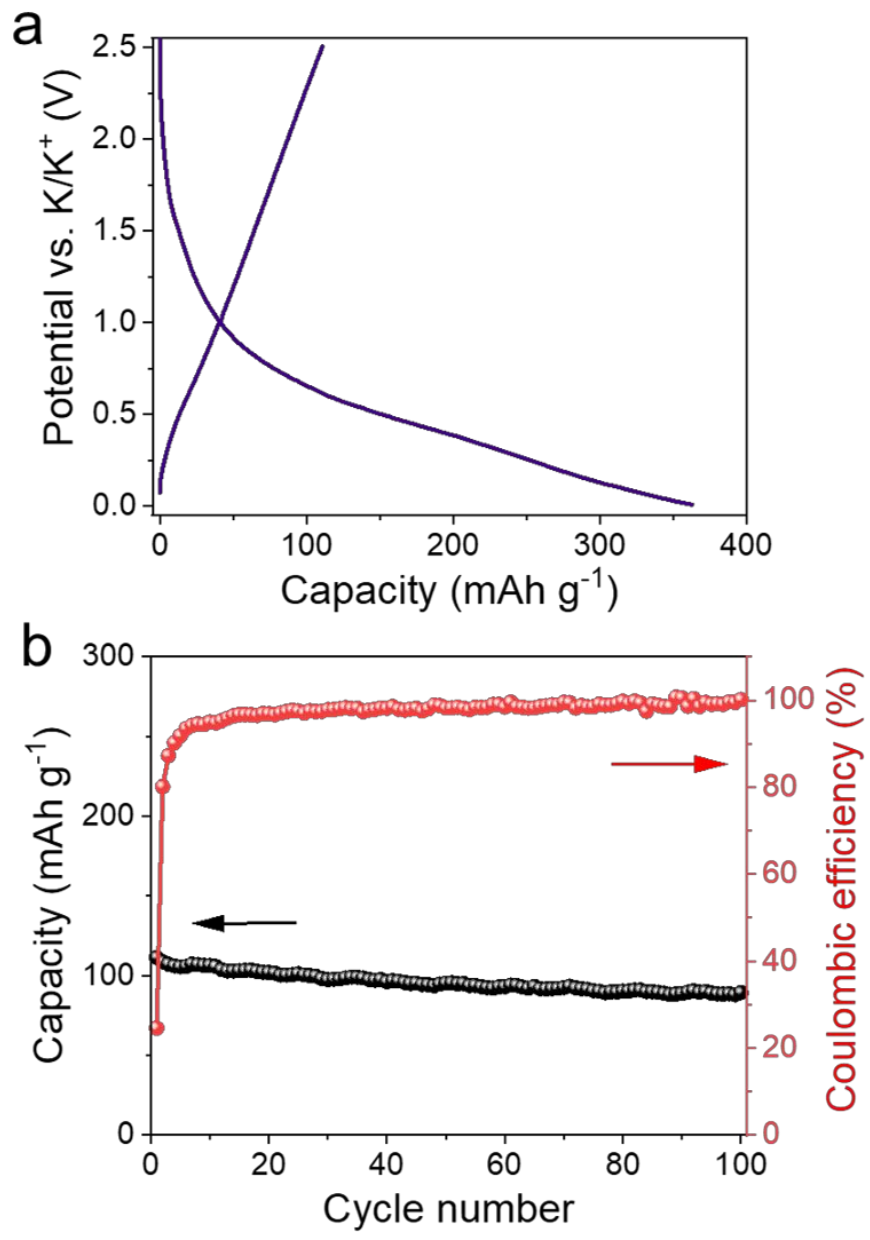

Figure S13. (a) First discharge and charge profiles and (b) cycling performance of the $\mathrm{Ti}_{3} \mathrm{C}_{2} \mathrm{~T}_{\mathrm{x}} /$ graphene electrode at a current density of $0.1 \mathrm{~A} \mathrm{~g}^{-1}$. 


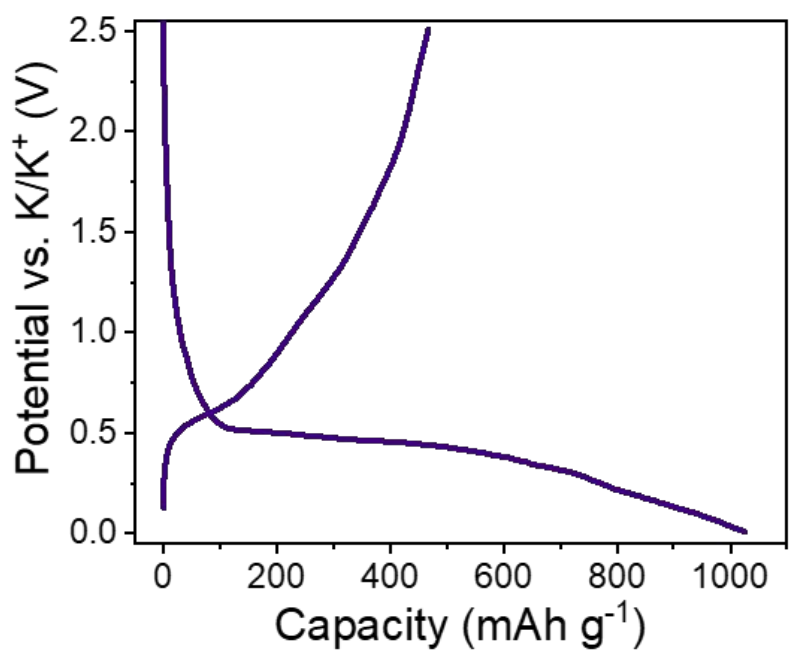

Figure S14. First discharge and charge profiles of Sb electrode at $0.1 \mathrm{~A} \mathrm{~g}^{-1}$. 


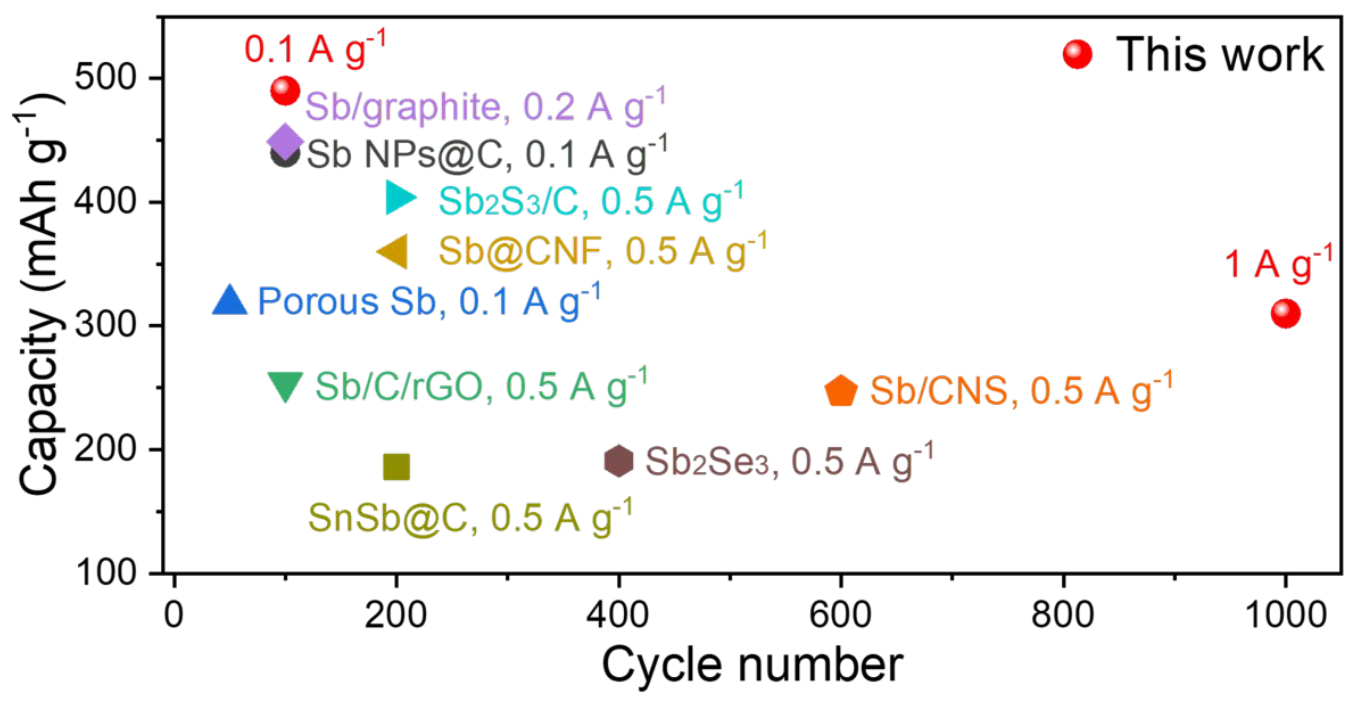

Figure S15. Comparison long-term cycling performance of the Sb SQ@MA with some other reported Sb-based anodes, including Sb/graphite, ${ }^{5} \mathrm{Sb}$ NPs $@ \mathrm{C},{ }^{6} \mathrm{Sb}_{2} \mathrm{~S}_{3} / \mathrm{C},{ }^{7}$ $\mathrm{Sb} @ \mathrm{CNF},{ }^{8}$ porous $\mathrm{Sb},{ }^{9} \mathrm{Sb} / \mathrm{C} / \mathrm{rGO},{ }^{10} \mathrm{Sb}_{2} \mathrm{Se}_{3},{ }^{11} \mathrm{Sb} / \mathrm{CNS},{ }^{12}$ and $\mathrm{SnSb} @ \mathrm{C}^{13}$ composites. 


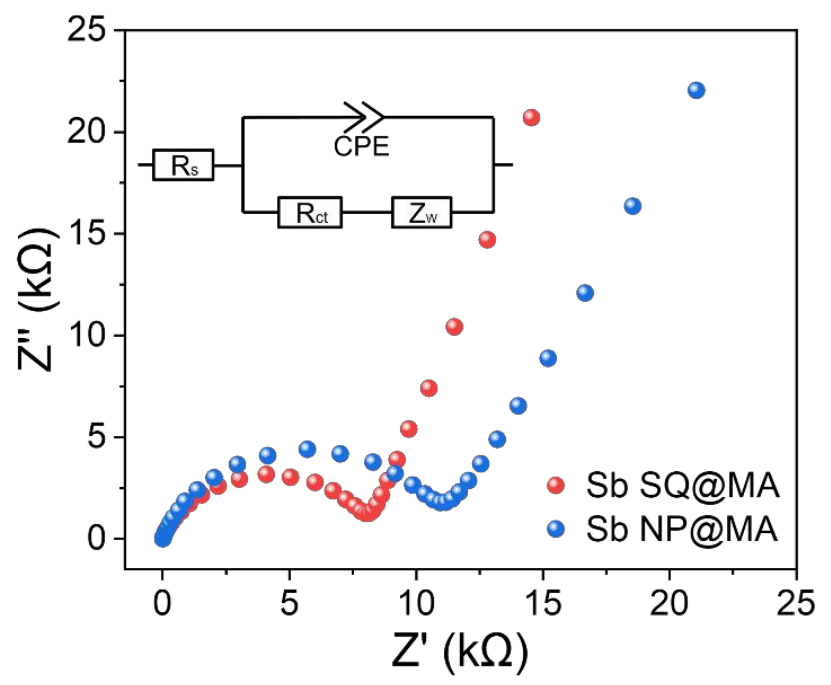

Figure S16. Nyquist plots of the Sb SQ@MA and Sb NP@MA composites; inset is the corresponding equivalent circuit to fit the results. $\mathrm{R}_{\mathrm{s}}$ reflects the resistance of cell components and the electrolyte, $\mathrm{R}_{\mathrm{ct}}$ represents the charge transfer impedance; $\mathrm{CPE}$ is a constant-phase element of the electrolyte and electrode interface, which accounts for the depressed semicircle in the measured spectra; and $Z_{\mathrm{w}}$ is Warburg impedance, which accounts for the inclined line and reflecting sodium ion transfer process in the electrode materials. 


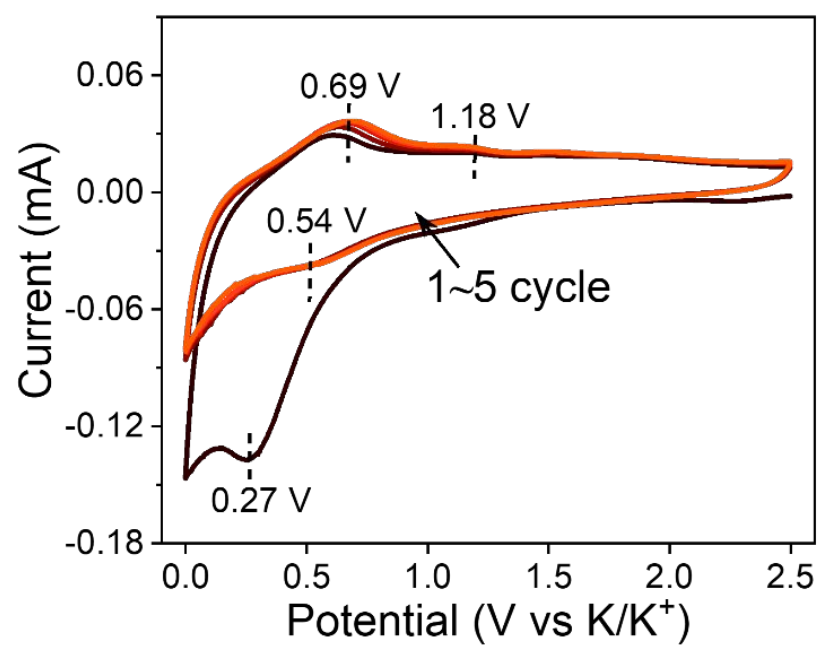

Figure S17. Initial five cyclic voltammetry curves of the Sb SQ@MA electrode at a scan rate of $0.1 \mathrm{mV} \mathrm{s}^{-1}$. 

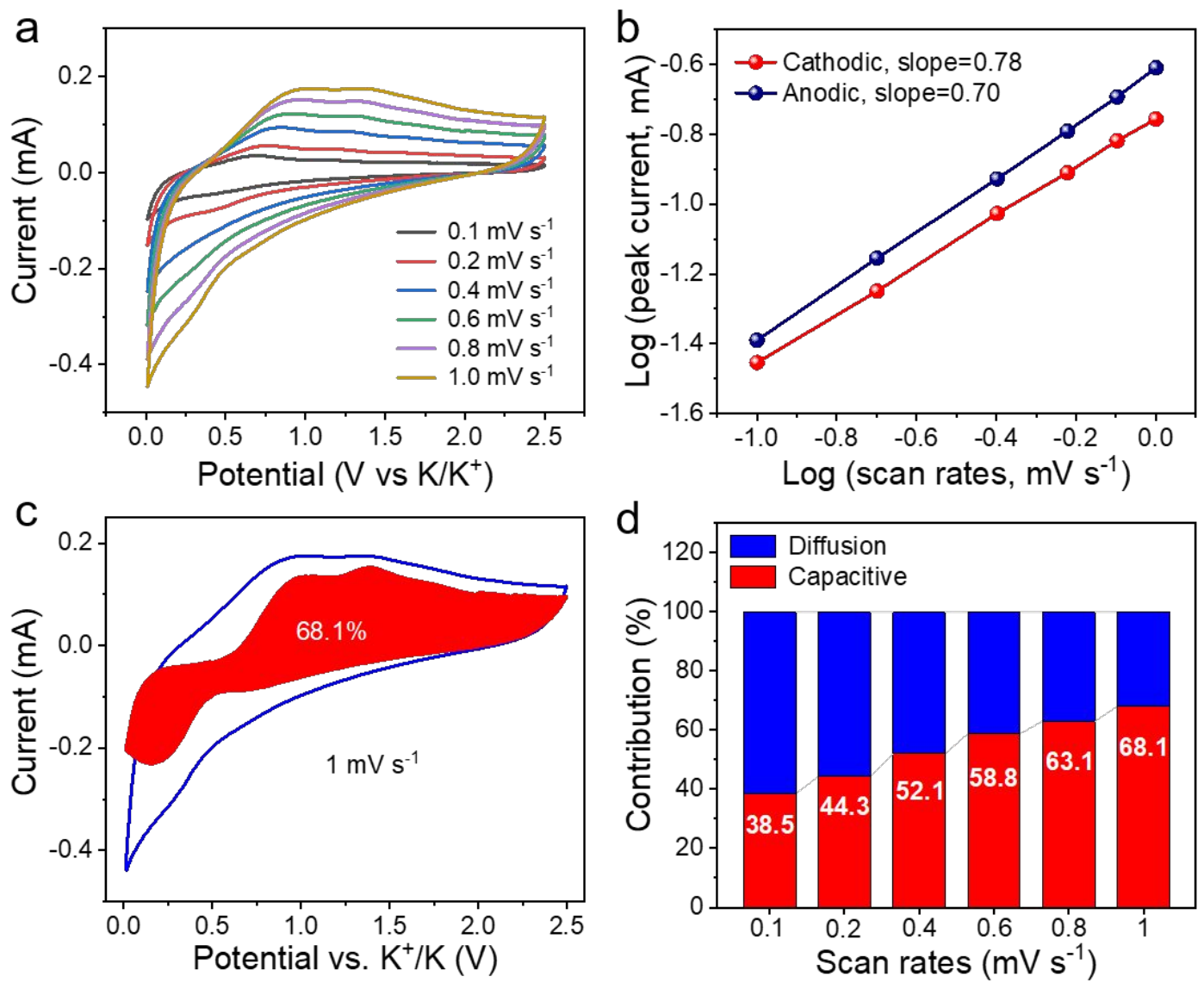

Figure S18. Electrochemical reaction kinetics analysis of the Sb SQ@MA composite.

(a) CV curves at different scan rates. (b) Relationship between peak currents and scan rates. (c) $\mathrm{CV}$ profile collected at $1 \mathrm{mV} \mathrm{s}^{-1}$ and illustration of capacitive (red area). (d) Chart of capacitance- and diffusion-controlled contribution ratios at different scan rates.

Based on the relationship between the peak currents $(i)$ and scan rates $(v), i=\mathrm{a} v^{\mathrm{b}}$, the $b$ value representing the charge storage mechanism can be obtained from Figure $\mathrm{S} 18 \mathrm{a}$. When $\mathrm{b}=0.5$, the reaction is completely a diffusion-controlled process; when $\mathrm{b}=1$, it is a capacitance-controlled process. As shown in Figure S18b, the b value of $\mathrm{Sb}$ SQ@MA is 0.78 , indicating a mixed diffusion and capacitance-dominated reaction kinetics. 
The specific diffusion and capacitance contribution at a fixed scan rate can be quantified through the following equation: $i(V)=k_{1} v+k_{2} v^{1 / 2}$, where $\mathrm{i}(V), k_{1} v$ and $k_{2} v^{1 / 2}$ represent the current at a fixed voltage, capacitive current, and ion-diffusion current, respectively. Figure S18c exhibits a typical CV curve for capacitive current (red region) in comparison to total current (blue line) at $1 \mathrm{mV} \mathrm{s}^{-1}$. The diffusion process becomes predominant at around $0.51 \mathrm{~V}$, corresponding to the alloying-dealloying process of $\mathrm{Sb}$ quantum dots. By contrast, the capacitive process dominants the charge storage behavior at other voltage regions. The capacitive contribution at a fixed scan rate can be obtained by computing the capacitive current area percentage in the total CV region. The capacitive contributions of the composite electrodes gradually grow along with the increased scan rates, and it reaches $68.2 \%$ at $1 \mathrm{mV} \mathrm{s}^{-1}$, implying a pseudocapacitancedominated behavior of Sb SQ@MA composite at high rates (Figure S18d). 
a

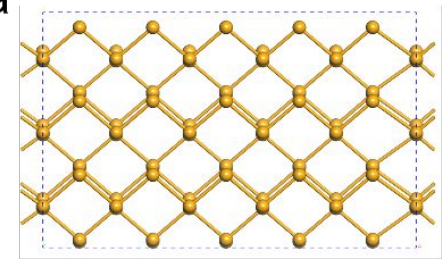

d

$\mathrm{Sb}(012)$

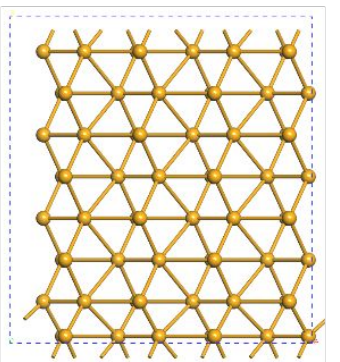

$\mathrm{Sb}(101)$ b

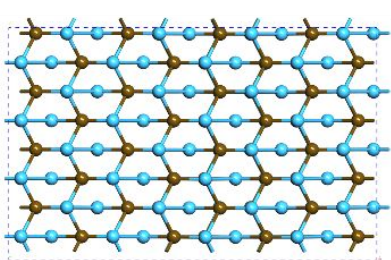

$\mathrm{Ti}_{3} \mathrm{C}_{2}(012)$

e

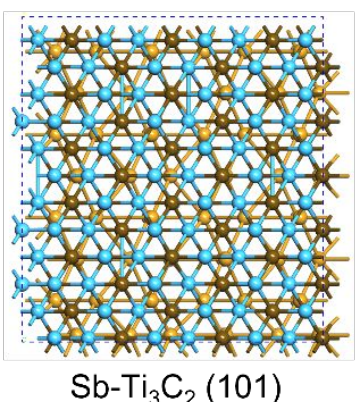

C

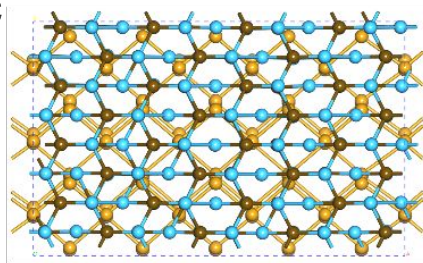

$\mathrm{Sb}-\mathrm{Ti}_{3} \mathrm{C}_{2}(012)$

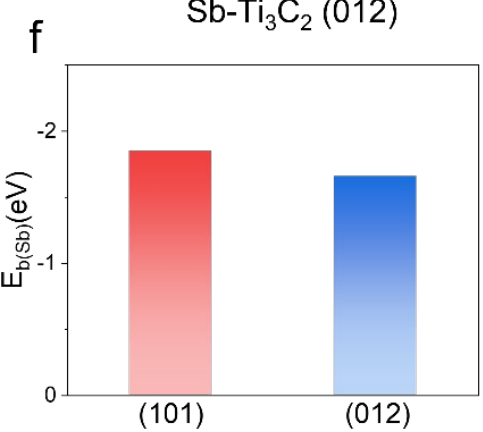

Figure S19. Theoretical study of the structural stability of $\mathrm{Sb}-\mathrm{Ti}_{3} \mathrm{C}_{2}$ composite in (101) and (012) planes. Top views of the (a) $\mathrm{Sb}$, (b) $\mathrm{Ti}_{3} \mathrm{C}_{2}$ and (c) $\mathrm{Sb}-\mathrm{Ti}_{3} \mathrm{C}_{2}$ in (012) plane. Top views of the (d) $\mathrm{Sb}$ and (e) $\mathrm{Sb}-\mathrm{Ti}_{3} \mathrm{C}_{2}$ in (101) plane. (f) Formation energies per $\mathrm{Sb}$ atom of the $\mathrm{Sb}-\mathrm{Ti}_{3} \mathrm{C}_{2}$ in (012) and (101) plane, respectively.

\section{References}

1. Kresse; Hafner, Ab initio molecular-dynamics simulation of the liquid-metalamorphous-semiconductor transition in germanium. Physical review. B, Condensed matter 1994, 49 (20), 14251-14269.

2. Kresse; Furthmuller, Efficient iterative schemes for ab initio total-energy calculations using a plane-wave basis set. Physical review. B, Condensed matter 1996, 54 (16), 11169-11186.

3. Perdew; Burke; Wang, Generalized gradient approximation for the exchangecorrelation hole of a many-electron system. Physical review. B, Condensed matter 1996, 54 (23), 16533-16539.

4. Blochl, Projector augmented-wave method. Physical review. B, Condensed matter 1994, 50 (24), 17953-17979.

5. Liu, Q.; Fan, L.; Chen, S.; Su, S.; Ma, R.; Han, X.; Lu, B., Antimony-Graphite Composites for a High-Performance Potassium-Ion Battery. Energy Technol. 2019, 7 (10), 1900634. 
6. Wang, H.; Wu, X.; Qi, X.; Zhao, W.; Ju, Z., Sb nanoparticles encapsulated in 3D porous carbon as anode material for lithium-ion and potassium-ion batteries. Materials Research Bulletin 2018, 103, 32-37.

7. Liu, Y.; Tai, Z.; Zhang, J.; Pang, W. K.; Zhang, Q.; Feng, H.; Konstantinov, K.; Guo, Z.; Liu, H. K., Boosting potassium-ion batteries by few-layered composite anodes prepared via solution-triggered one-step shear exfoliation. Nat. Commun. 2018, 9 (1), 3645 .

8. Liu, D.; Yang, L.; Chen, Z.; Zou, G.; Hou, H.; Hu, J.; Ji, X., Ultra-stable Sb confined into N-doped carbon fibers anodes for high-performance potassium-ion batteries. Sci. Bull. 2020, 65 (12), 1003-1012.

9. An, Y.; Tian, Y.; Ci, L.; Xiong, S.; Feng, J.; Qian, Y., Micron-Sized Nanoporous Antimony with Tunable Porosity for High-Performance Potassium-Ion Batteries. ACS Nano 2018, 12 (12), 12932-12940.

10. Ko, Y. N.; Choi, S. H.; Kim, H.; Kim, H. J., One-Pot Formation of Sb-Carbon Microspheres with Graphene Sheets: Potassium-Ion Storage Properties and Discharge Mechanisms. ACS Appl. Mater. Interfaces 2019, 11 (31), 27973-27981.

11. Yi, Z.; Qian, Y.; Tian, J.; Shen, K. Z.; Lin, N.; Qian, Y. T., Self-templating growth of $\mathrm{Sb}_{2} \mathrm{Se}_{3} @ \mathrm{C}$ microtube: a convention-alloying-type anode material for enhanced Kion batteries. J. Mater. Chem. A 2019, 7 (19), 12283-12291.

12. Han, Y.; Li, T.; Li, Y.; Tian, J.; Yi, Z.; Lin, N.; Qian, Y., Stabilizing antimony nanocrystals within ultrathin carbon nanosheets for high-performance K-ion storage. Energy Storage Mater. 2019, 20, 46-54.

13. Wang, Z. Y.; Dong, K. Z.; Wang, D.; Luo, S. H.; Liu, Y. G.; Wang, Q.; Zhang, Y. H.; Hao, A. M.; Shi, C. S.; Zhao, N. Q., A nanosized SnSb alloy confined in N-doped 3D porous carbon coupled with ether-based electrolytes toward high-performance potassium-ion batteries. J. Mater. Chem. A 2019, 7 (23), 14309-14318. 